\title{
SUSPECTED PESTICIDE POISONING: A BACK-OF-THE-ENVELOPE HEALTH RISK ASSESSMENT
}

\section{Geoffrey Richards \\ Environmental Health Branch \\ NSW Department of Health}

Not all health risk assessment is of a formal and extensive nature. At times a 'back-of-the-envelope', or quick screening assessment, based on few or limited data may be appropriate. It may consist solely of discussion with a member of the public over the phone concerning a soil, water, food or air sample and its comparison with some national or internationally accepted standard or guideline; or it may deserve slightly deeper consideration. This article describes such an assessment, using the example of a suspected pesticide poisoning - an environmental health issue typical of those encountered by the Environmental Health Branch and the public health units each day.

\section{BACKGROUND}

A woman who purchased a home in southern Sydney had the sub-floor area treated for termites, by a licensed pest control company, prior to moving in. She alleged that soon after entering the house with her primary school age children she experienced nausea and headache. After vacating the house for a few days she returned, but could still detect an odour and again felt nauseous. The Pesticide Branch of the NSW Environment Protection Authority (EPA), was contacted and an investigation was initiated.

The house was constructed on short piers with little subfloor ventilation, and the pest control operator stated that he used bifenthrin, a synthetic pyrethroid termiticide. Soil samples taken from under the house indicated an accumulation of chemicals, including traces of organochlorine pesticides, from successive termiticide treatments over many years; not an unusual condition for older houses in Sydney. Analyses strongly suggested a very recent treatment with bifenthrin on top of a treatment with chlorpyrifos, an organophosphate pesticide, undertaken within the previous one to two years or possibly longer, depending on the soil conditions that existed.

The EPA took air samples from a child's bedroom, which had been identified as a room having the strongest odour. A Gilian air sampler and ORBO 49 'puffer' tube was used to collect a 24-hour, one litre (L)/minute sample. The ORBO 49 tube is sensitive to synthetic pyrethroids and is very sensitive to organophosphates. Results of the air sample showed 3.5 micrograms $(\mu \mathrm{g})$ of chlorpyrifos in 1,440 litres of air and no detection of bifenthrin. The EPA, through the South Eastern Sydney Public Health Unit, requested an assessment of health risk should an individual be constantly exposed to chlorpyrifos in the air at the concentrations measured during sampling.

\section{CHLORPYRIFOS}

Chlorpyrifos is a member of the organophosphorus class of chemicals and is registered for use in various formulations as a termiticide. It has been used in Australia for over 30 years and was recently extensively reviewed by the National Registration Authority for Agricultural and Veterinary Chemicals (NRA) under its Existing Chemicals Review Program. ${ }^{1}$ The toxicology and assessment of risks, particularly from non-occupational exposure to chlorpyrifos, has also been comprehensively addressed in several papers published recently.,3

Like other organophosphorus pesticides, chlorpyrifos inhibits the cholinesterase enzyme systems essential in the normal functioning of the nervous system. The most commonly reported effects of chlorpyrifos poisoning include: headache, nausea, dizziness, salivation, excess sweating, blurred vision, chest tightness, muscle weakness, abdominal cramps, and diarrhoea.

If occupational exposure is discounted, most effects from entry into areas treated with chlorpyrifos for termites are reported to be more likely a result of odour rather than the ability of the termiticide to inhibit cholinesterases. ${ }^{2}$ This may be due to the active constituent itself, which has a distinctive sulphurous odour, or to volatile organic or petroleum solvents, with which chlorpyrifos and pyrethroids such as bifenthrin are usually formulated, and that may smell as they evaporate during and after application. ${ }^{4}$

\section{ASSESSING RISKS}

The results of the bedroom air sample showed $3.5 \mu \mathrm{g}$ of chlorpyrifos in 1,440 $\mathrm{L}$ of air collected over 24 hours at a sampling rate of one $\mathrm{L} /$ minute.

Therefore, chlorpyrifos concentration:

$$
\begin{aligned}
= & (3.5 \mu \mathrm{g} / 1,440 \text { minutes }) \times(1 \text { minute } / 1 \mathrm{~L}) \times \\
& \left(1,000 \mathrm{~L} / 1 \mathrm{~m}^{3}\right) \\
= & (0.0024) \times(1) \times(1,000) \\
= & \mathbf{2 . 4} \mu \mathrm{g} / \mathbf{m}^{3} .
\end{aligned}
$$

For comparison, the Australian Occupational Air Standard, ${ }^{5}$ based on an average airborne concentration of chlorpyrifos over a normal eight-hour working day for a five-day working week, and which according to present knowledge should not cause adverse health effects, is 0.2 milligrams (mg) $/ \mathrm{m}^{3}$ or: $200 \mu \mathrm{g} / \mathrm{m}^{3}$. 
Comparisons with occupational exposure criteria; however, should be made with care, as appropriate adjustments have not been made for differing durations of exposure or for susceptible groups such as children.

The United States Environmental Protection Agency has developed very conservative risk-based concentrations of contaminants for screening purposes. ${ }^{6}$ The risk-based concentration for chlorpyrifos in ambient air, which will not pose either an acute or long term threat to human health, is: $11 \mu \mathrm{g} / \mathrm{m}^{3}$.

Another quick form of comparison that can be made is by relating the amount of chlorpyrifos calculated to have been inhaled in the bedroom with the acceptable daily intake (ADI) of the chemical. The ADI for humans is considered to be a level of intake of a chemical over an entire lifetime without any appreciable risk to health. Regardless of the route of exposure (oral, dermal, or inhalation) the toxic effects of chlorpyrifos are similar.

The Australian ADI for chlorpyrifos is $0.003 \mathrm{mg} / \mathrm{kilogram}$ (kg)/bodyweight (bw)/day. ${ }^{1,7}$ This is based on a "no observable adverse effect level' (NOAEL) for plasma cholinesterase inhibition of $0.03 \mathrm{mg} / \mathrm{kg}$ bw/day derived from human studies and is more conservative than estimates based on inhibition of red cell or brain acetylcholinesterase. Thus, the ADI itself is conservatively based with a safety margin built in. For comparison the World Health Organization ADI is $0.01 \mathrm{mg} / \mathrm{kg}$ bw/day.

The children of the house purchaser were primary school age. Using an enHealth exposure default value, ${ }^{8}$ assume that a child of 10 years is present in the bedroom for 24 hours of the day with a daily inhalation volume of $15 \mathrm{~m}^{3}$ of air, therefore estimated chlorpyrifos exposure:

$$
\begin{aligned}
& =(15) \times(2.4 \mu \mathrm{g}) \\
& =\mathbf{3 6} \boldsymbol{\mu g} / \mathbf{d a y} .
\end{aligned}
$$

Add chlorpyrifos intake from food of $1.1 \mu \mathrm{g} /$ day derived from the mean estimated daily dietary exposure of 12 year old children. ${ }^{9}$ (No estimated intake for 10 year olds was found).

\section{Estimated chlorpyrifos exposure:}

$$
=36 \mu \mathrm{g} / \mathrm{day}+1.1 \mu \mathrm{g} / \mathrm{day}
$$

$=\quad 37.1 \mu \mathrm{g} /$ day intake of chlorpyrifos for child in bedroom.
No intake of chlorpyrifos from drinking water need be considered because Sydney Water monitors for pesticides and has not detected them in raw water sources. Dermal intake would also be limited because application of the chemical was sub-floor and not to the general living area.

In comparison assume a 10 year old child weighing $32 \mathrm{~kg}$ is exposed to the Australian ADI for chlorpyrifos:

$$
\begin{aligned}
&(32) \times(0.003 \mathrm{mg} / \mathrm{kg}) \\
&= 0.096 \mathrm{mg} / \mathrm{day} \text { or } \\
&= \mathbf{9 6 . 0 0} \boldsymbol{\mu g} / \mathbf{d a y} \text { acceptable daily intake of } \\
& \text { chlorpyrifos for this child. }
\end{aligned}
$$

The estimated intake for a primary school child present in the house is therefore approximately one third of the acceptable daily intake.

\section{CONCLUSION}

If the air sampling and analyses were accurate, and the bedroom was an appropriate site in the house for testing, the results indicate that even when using conservative parameters, constant exposure to levels of chlorpyrifos detected in the bedroom would not cause either acute or chronic health effects.

The most likely explanation for the purchaser's symptoms would appear to be exposure to odours; either through application of the bifenthrin or through reactivation by wetting of the previous chlorpyrifos treatment. Although the effects of the odour were unpleasant, odours from chlorpyrifos and bifenthrin formulations per se are not known to cause toxicological effects unless accompanied by harmful concentrations of the chemicals. In this example, that was not the case. The broader issue of pesticide odours and their effects, however, is still of concern and has recently been given some attention by the National Registration Authority for Agricultural and Veterinary Chemicals (NRA) and the Commonwealth Department of Health and Ageing.

The house was constructed on short piers with little subfloor ventilation and this coupled with high humidity may partially explain the lingering smell.

A citrus deodoriser was used and fans installed underneath the home to try to disperse the odour. 


\section{ACKNOWLEDGEMENTS}

Thank you to John Hall of the NSW Environmental Protection Authority for providing background material.

\section{REFERENCES}

1. National Registration Authority for Agricultural and Veterinary Chemicals. Review of Chlorpyrifos: Interim Report. Canberra: National Registration Authority for Agricultural and Veterinary Chemicals Review Series 00.5, September 2000. Online at www.nra.gov.au/chemrev/chlor.shtml.

2. Cochran RC. Appraisal of risks from nonoccupational exposure to chlorpyrifos. Regul Toxicol Pharmacol 2002; 35: 105-121.

3. Gemert Mv, Dourson M, Moretto A, Watson M. Use of human data for the derivation of a reference dose for chlorpyrifos. Regul Toxicol Pharmacol 2001; 33: 110-116.

4. Therapeutic Goods Administration and Department of Health and Aged Care. Termite Protection: Available Treatments and Hazard Information About Termiticides. Canberra: Therapeutic Goods Administration and Department of Health and Aged Care, 2002.
5. National Occupational Health and Safety Commission. Exposure Standards for Atmospheric Contaminants in the Occupational Environment: 3rd Edition. Canberra: National Occupational Health and Safety Commission, 1995.

6. Smith RL. Risk-based concentrations: Prioritizing environmental problems using limited data. Toxicology 1996; 106: 243-266.

7. Therapeutic Goods Administration and Commonwealth Department of Health and Ageing. ADI List: Acceptable Daily Intakes for Agricultural and Veterinary Chemicals. Current to 31 December 2002. Canberra: Therapeutic Goods Administration and Commonwealth Department of Health and Ageing, 2003.

Regularly updated at www.health.gov.au:80/tga/docs/html/ adi.htm.

8. Department of Health and Ageing and enHealth Council. Environmental Health Risk Assessment. Guidelines for assessing human health risks from environmental hazards. Canberra, Commonwealth Department of Health and Ageing and enHealth Council, 2002.

9. Australian New Zealand Food Authority. The 19th Australian Total Diet Survey 1998. Canberra: Australian New Zealand Food Authority, 2001. 